\title{
Coastal havoc boosts jellies
}

\section{Five-year Chinese study suggests that human activity made gelatinous outbreaks worse.}

\section{BY JANE QIU IN QINGDAO}

C $T^{\mathrm{t}}$ was a truly gelatinous world," says marine ecologist Sun Song, recalling a

jellyfish outbreak last year in the Yellow

Sea off China's eastern coast. "The slimy monsters were everywhere, their long tentacles fluttering ferociously in the rolling waves." Such blooms have repeatedly choked Chinese waters in the past decade, posing substantial threats to tourism, fisheries and coastal facilities such as chemical plants and nuclear power stations.

Jellyfish blooms have probably struck the world's seas periodically for hundreds of millions of years. But researchers suspect that human activity has made them worse, with knock-on effects on marine ecosystems and especially on fish, because jellyfish compete with fish for food and feed on their larvae. Now, one of the largest studies of jellyfish blooms so far - involving laboratory testing, ocean surveys and field experiments - has found direct evidence linking the proliferation of jellyfish to human disturbances along the coast, especially the disruption of sea-floor ecosystems.

The five-year, US\$4.5-million initiative started work in 2010 led by Sun, who is director of the Chinese Academy of Sciences' Institute of Oceanology in the coastal city of Qingdao. Sun's team, involving eight institutions and more than 100 researchers, presented its latest results earlier this month at the World Conference on Marine Biodiversity, also in Qingdao. China's waters are not the only ones to have had jellyfish outbreaks in recent years, so the results "could help to tackle similar problems in other parts of the world" such as the Mediterranean or the Caspian Sea, says Mark Costello, a marine ecologist at the University of Auckland in New Zealand.

The survey shows that Chinese coasts are plagued primarily by three jellyfish species: Aurelia aurita, Cyanea nozaki and the most damaging one, the giant Nemopilema nomurai, which can grow to 2 metres in diameter and weigh as much as 200 kilograms.

Jellyfish are most recognizable in the shortlived 'medusa' stage of their life cycles, when they swim freely and reproduce sexually. But they also go through a stage in which they are bound to the sea floor as 'polyps'. These can live for years and reproduce asexually, budding new medusae. Most research so far has focused on the medusa stage, but "the key to jellyfish outbreaks may lie in the polyps", says Sun.

Polyps are notoriously difficult to find and

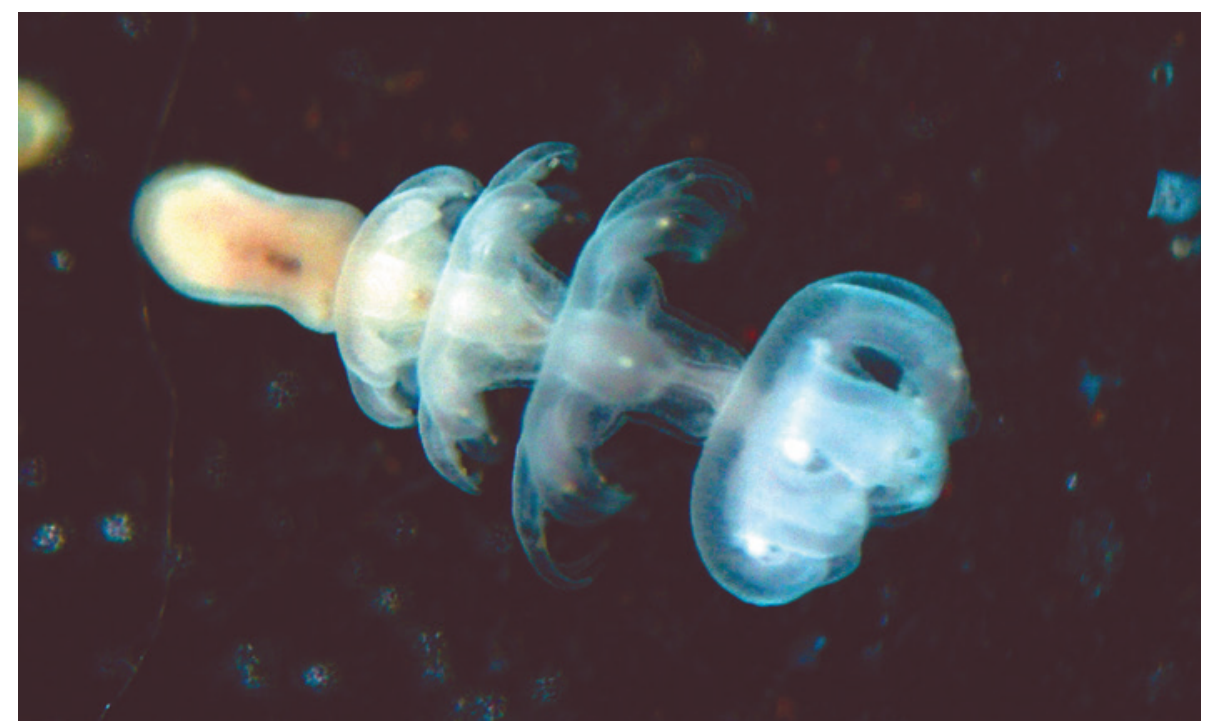

A polyp of Nemopilema nomurai, 1 millimetre long, will give rise to medusae more than 2 metres across.

collect: they are transparent and easy to break, and can be just micrometres long. "Numerous attempts by scuba diving, underwater robots and dredging up the sediments have led to nothing," Sun says. So the team turned to the jellyfish in the oceanology institute's aquarium. The researchers grew polyps on hard surfaces such as glass, plastic or stone in the laboratory and then lowered the slabs onto the seabed at half a dozen coastal locations, to see if specific environmental factors would spur a mini-outbreak.

As Sun reported at the conference, polyps of all three species tended to sprout medusae when sea-bottom temperatures were about $10-15^{\circ} \mathrm{C}$. The blooms were greatly enhanced by extreme temperature swings. Moreover, more medusae formed in waters that had fewer bottom dwellers, or 'benthos' - animals such as starfish, sea slugs, shrimp and fish - and greater environmental disturbance. Nutrient overloads from sewage and agricultural run-off, and construction of infrastructure such as ports and bridges, seemed to help the jellyfish to thrive.

The findings point to a link between the gelatinous scourges and coastal disturbances in China caused by overfishing, bottom trawling and oxygen depletion following algal blooms, as well as coastal development and increasingly frequent extreme-weather events, says Costello. Moreover, a decline in both the number and the diversity of benthos in the past 50 years may have also contributed, says Xu Kuidong, a marine ecologist at the Institute of Oceanology. Benthos that feed on polyps "are the key biological control of jellyfish populations", he says.
The ocean currents that skirt China's coast can affect benthos by changing temperatures and nutrient concentrations, so a broader approach will be necessary to unveil the true causes of jellyfish outbreaks, says Sun. In April, he and his colleagues launched a fiveyear, \$165-million project to study ocean currents. By measuring the motion of currents at depths of up to 6,000 metres, and learning how ecosystems respond, the researchers hope to piece together how local and regional factors combine to cause blooms. "This might allow us to forecast - and even prevent - a forthcoming outbreak," says Sun.

And in May, an international collaboration launched the Jellyfish Database Initiative (JeDI), which will provide global, open-access data on jellyfish abundances and associated environmental factors. Such projects - as well as more-detailed studies of polyps - will attempt to improve understanding of outbreaks and the contribution of natural variations and human factors to changes in jelly populations around the world, says Cathy Lucas, a marine biologist at the University of Southampton, UK, who contributes to JeDI.

Sun says that increasing rates of jellyfish outbreaks in Chinese waters might be an indicator of worsening ecosystem health. Over the past 500 million years, the creatures have survived countless climatic and environmental upheavals - including all five known mass-extinction events, he points out. "When ecosystems deteriorate, they are likely to thrive when others fail." - 